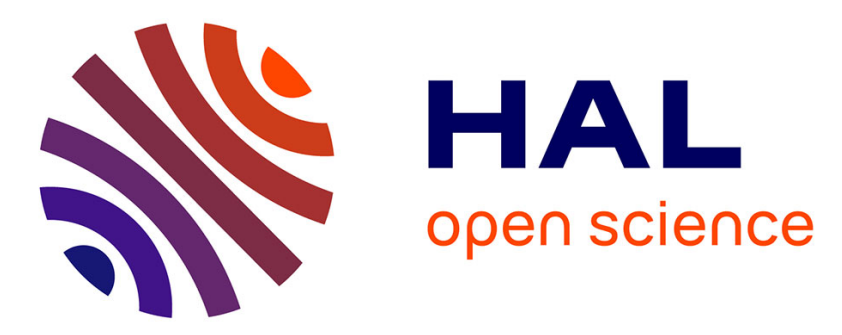

\title{
Discrimination of isomeric trisaccharides and their relative quantification in honeys using trapped ion mobility spectrometry
}

Cédric Przybylski, Véronique Bonnet

\section{- To cite this version:}

Cédric Przybylski, Véronique Bonnet. Discrimination of isomeric trisaccharides and their relative quantification in honeys using trapped ion mobility spectrometry. Food Chemistry, 2021, 341, pp.128182. 10.1016/j.foodchem.2020.128182 . hal-03146652

\section{HAL Id: hal-03146652 \\ https://hal.sorbonne-universite.fr/hal-03146652}

Submitted on 19 Feb 2021

HAL is a multi-disciplinary open access archive for the deposit and dissemination of scientific research documents, whether they are published or not. The documents may come from teaching and research institutions in France or abroad, or from public or private research centers.
L'archive ouverte pluridisciplinaire HAL, est destinée au dépôt et à la diffusion de documents scientifiques de niveau recherche, publiés ou non, émanant des établissements d'enseignement et de recherche français ou étrangers, des laboratoires publics ou privés. 


\section{Discrimination of isomeric trisaccharides and their relative}

2 quantification in honeys using Trapped Ion Mobility Spec-

3 trometry

4 Cédric Przybylski* ${ }^{\dagger}$ and Véronique Bonnet ${ }^{*}$

$5 \nmid$ Sorbonne Université, CNRS, Institut Parisien de Chimie Moléculaire, IPCM, 4 Place Jussieu, 675005 Paris, France.

$7 \quad$ E-mail: cedric.przybylski@ sorbonne-universite.fr

8

$9 \ddagger$ Université de Picardie Jules Verne, Laboratoire de Glycochimie, des Antimicrobiens et des

10 Agroressources, LG2A, CNRS UMR 7378, 33 rue Saint Leu, 80039 Amiens, France.

11

12

13 


\section{ABSTRACT}

15 Carbohydrates play a myriad of critical roles as key intermediaries for energy storage, cell wall

16 constituents, or also fuel for organisms. The deciphering of multiple structural isomers based on

17 the monosaccharides composition (stereoisomers), the type of glycosidic linkages (connectivity)

18 and the anomeric configuration ( $\alpha$ and $\beta$ ), remains a major analytical challenging task. The pos-

19 sibility to discriminate 13 underivatized isomeric trisaccharides were reported using electrospray

20 ionization coupled to trapped ion mobility spectrometry (ESI-TIMS). After optimization of scan

21 ratio enhancing both the mobility resolving power (R) and resolution (r), fingerprints from 5 dif-

22 ferent honeys were obtained. Seven trisaccharides with relative content varying from 1.5 to

$2358.3 \%$, were identified. It was demonstrated that their relative content and/or their ratio could be

24 used to ascertain origin of the honeys. Moreover, such direct approach constitutes an alternative

25 tool to current longer chromatographic runs, paving the way to a transfer as suitable routine 26 analysis.

28 Keywords (6 max): ion-mobility, carbohydrates, trisaccharides, honey, ESI-TIMS, collision cross 29 section. 


\section{INTRODUCTION}

32 Carbohydrates or glycans are ubiquitous and the most abundant biological polymers in nature

33 occurring in many important biological processes (Varki, 2015). Their role and function are be-

34 yond key biological intermediary for energy storage and fuel for organisms. Indeed, they can, for

35 example, serve as building blocks for synthesis of higher macromolecules (nucleotides, glyco-

36 proteins, ...) or by modulating the molecular recognition in many physio-pathological processes

37 (Marth, 2008; Varki, 2015). Moreover, they are also the most rapidly evolving class of bio-

38 molecules through the evolution. Although it motivates numerous efforts for their characteriza-

39 tion, their structural deciphering remains a critical bottleneck. Indeed, carbohydrates sequencing

40 poses a major analytical challenge due to their inherent structural diversity, which is subject to a

41 pressing need emphasized by national research councils (EGSF and IBCarb Network \& Euro-

42 pean Science Foundation, 2014; National Research Council (US), 2012). Such complexity is

43 mainly due to:

44 i) monosaccharides composition i.e. the carbohydrate based building blocks which are often

45 stereoisomers that differ only in their stereochemistry at one particular carbon atom (glucose

46 (Glc); galactose (Gal); mannose (Man)...).

47 ii) type of glycosidic linkages (connectivity) established between backbones of two building

48 blocks, leading to linear or branched structures with diverse regioisomers.

49 iii) anomeric configuration ( $\alpha$ and $\beta$ ), relative to the stereogenic centre appearing consecutively

50 to a glycosidic bond formation. As example, considering a sequence of three monomers, more

51 than $1.13 \times 10^{7}$ trisaccharides can be theoretically obtained (Laine, 1994). Historically, NMR is

52 the reference method to determine the configurational information of carbohydrates, but require

53 mg scale amounts, and allows only relative detection limit of $\approx 3-5 \%$, restricting the identification 
54 of small amounts of coexisting isomers (Duus et al., 2000). Mass spectrometry (MS) is also very

55 used to identify and elucidate carbohydrates sequence, since it accurately and rapidly measure a

56 mass-to-charge ratio $(\mathrm{m} / \mathrm{z})$, with sub- $\mu$ g requirement, but intrinsic limit arising for stereoisomers

57 discrimination ability (Dell \& Morris, 2001). Further information can be also extracted regarding

58 connectivity and so on sequence can be obtained using MS and iterative fragmentation (Ashline

59 et al., 2007; Carroll et al., 1995; Riggs et al., 2018; Schindler et al., 2017). Nevertheless, as re-

60 gards isomers, most of time very similar fragmentation pathways are obtained, impairing rigor-

61 ous discrimination. Liquid chromatography (LC) with or without coupling to MS represents an

62 alternative way for configurational isomers differentiation, but can be restricted by resolving

63 power to track one given isomer within potential others in complex mixture (Lareau et al., 2015).

64 In addition, derivatization step is very often a mandatory condition (Hofmann et al., 2015; Hof-

65 mann \& Pagel, 2017). Recent IR or UV spectroscopies coupled to MS have proved their useful-

66 ness to obtain fingerprinting and delineate some anomeric forms (Ben Faleh et al., 2019; Mucha

67 et al., 2017; Riggs et al., 2018; Schindler et al., 2018; Gray et al., 2017). A promising approach

68 named ion mobility-MS (IM-MS) has been recently introduced and could overcome aforemen-

69 tioned limitations. IM-MS is a 2D method, which has potentiality to resolve glycan isomers

70 (Clowers et al., 2005; Hofmann \& Pagel, 2017; Zheng et al., 2017). Practically, their correspond-

71 ing ions are separated not only according to their $\mathrm{m} / \mathrm{z}$, but also as function of their size and shape

72 in the gas phase, thanks to the conversion of mobility into a collision cross section (CCS). IM-

73 MS has been successfully applied to the characterization of large variety of derivatized or un-

74 derivatized carbohydrates using travelling wave ion mobility (TWIM) (Harvey et al., 2018;

75 Clowers et al., 2005; Paglia et al., 2014). Hofmann et al. (2015) have elegantly demonstrated that

76 six pentylaminated disaccharides can be differentiated according to their stereochemistry, con- 
77 nectivity and anomeric configuration, but also that a relative anomeric content can be estimated

78 until $0.1 \%$. Other IM technologies such as field asymmetric ion mobility spectrometry (FAIMS)

79 or drift tube ion mobility spectrometry (DTIMS) was also investigated for glycan analysis

80 (Gabryelski \& Froese, 2003; Clowers et al., 2005; Gaye et al., 2015; Paglia et al., 2014; Xie et

81 al., 2020). Nonetheless, resolution of isomeric glycans by IM sometimes still fails to address

82 particular cases. Hence, the quest of improving IM separation efficiency remains one of the most

83 challenging field in IM-MS glycan analysis. To fulfil this objective, different strategies have

84 been deployed such as screening of various metal adduction (Huang \& Dodds, 2013, 2015; Xie

85 et al., 2020; Zheng, Zhang, et al., 2017), or the formation of diastereomeric adducts (Gaye et al.,

86 2016) or the development of more resolving instruments. In this sense, Nagy et al. (2018) have

87 tailored serpentine ion pathway, and McKenna et al. (2019) have developed a cyclic TWIM al-

88 lowing multipass separations. Recently, trapped ion mobility spectrometry (TIMS) was intro-

89 duced by Bruker. TIMS was notably successfully applied for the analysis of glycosaminoglycan

90 (Wei et al., 2019) as well as to permethylated lacto- $N$-tetrasaccharides (Pu et al., 2016). In the

91 present work, we report efforts to discriminate 13 isomeric trisaccharides (Figure S1) without

92 any derivatization using electrospray ionization-TIMS (ESI-TIMS). The ability of the newly

93 TimsTOFTM instrument to differentiate studied carbohydrates according to their structures and

94 shapes was investigated. Moreover, usefulness of approach was validated as regards some crite-

95 ria such as an unambiguous identification, rapid analysis, relative quantification features of

96 trisaccharides in five honeys. We therefore propose the use of our TIMS strategy to extract gly-

97 can distribution to serve as characteristic fingerprint applicable in several field such as foodstuff

98 samples quality control, which remains a major challenge. 
101 2.1. Standard Trisaccharides. D-cellotriose $(\geq 95 \%)$ and inulotriose $(\geq 90 \%)$, was purchased

102 from Megazyme (Berkshire, UK). Erlose ( $\geq 95 \%)$, laminaritriose ( $\geq 95 \%)$, D-gentianose $(\geq 97 \%)$,

103 1,4- $\beta$ - D-mannotriose $(\geq 95 \%)$ and 4'galactosyllactose $(\geq 95 \%)$ were purchased from Carbosynth

104 (Berkshire, UK). Maltotriose hydrate ( $\geq 95 \%)$, isomaltotriose ( $\geq 98 \%)$, D-panose ( $\geq 97 \%)$, D- $(+)$ -

105 melezitose monohydrate $(\geq 99.0 \%)$, D-(+)-raffinose pentahydrate $(\geq 98.0 \%)$, 1-kestose $(\geq 98.0 \%)$

106 were purchased from Sigma Aldrich (Saint-Quentin Fallavier, France).

107 2.2 Solvents. Methanol used for sample preparation was of LC grade and was purchased from 108 VWR (West Chester, PA, USA). Water was of ultrapure quality.

$109 \quad$ 2.3 Samples

$110 \quad$ 2.3.1 Solutions. Stock solutions were made at $10 \mathrm{mM}$ in water and then diluted to $10 \mu \mathrm{M}$ in 111 methanol/water $(1: 1 \mathrm{v} / \mathrm{v})$.

112 2.3.2 Honeys. 5 different honeys (3 from artisanal origin i.e. french lavender, rosemary and aca113 cia acquired directly from beekeepers and 2 from industrial source i.e. forest, eucalyptus).

114 All honeys are purchased from different regions of France such as Provence (french lavender and 115 rosemary), Alpine region (acacia), Auvergne region (forest) and Vosges mountains (eucalyptus).

116 Samples were prepared at $2 \%(\mathrm{w} / \mathrm{v})$ in methanol/water $(1: 1 \mathrm{v} / \mathrm{v})$, then further diluted by 1:2000

117 in the same solvent and passed through a $0.22 \mu \mathrm{m}$ filter to remove particulate matter, homoge118 nized by mechanical stirring and transferred to vials.

119 2.4 GC-MS analyses. Carbohydrate content in honey was controlled using the method described 120 by Sanz et al. (Sanz, M.L., Sanz, J., \& Martínez-Castro, I. (2004). See Supporting Information 121 for further details. 
$122 \quad 2.5$ TimsTOF ${ }^{\mathrm{TM}}$ Experiments. We used ESI-timsTOF ${ }^{\mathrm{TM}}$ (Bruker, Billerica, MA) operating with 123 oTOF control v5.0 software. The source temperature was hold at $200^{\circ} \mathrm{C}$, and the drying and 124 nebulizing gas $\left(\mathrm{N}_{2}\right)$ operate at a flow rate of $3 \mathrm{~L} \cdot \mathrm{min}^{-1}$ and at a pressure of 0.3 bar, respectively. 125 The instrument was calibrated using Tuning Mix G24221 (Agilent Technologies, Les Ulis, 126 France). Applied voltages were $+4 \mathrm{kV}$ and $-0.5 \mathrm{kV}$ for capillary and endplate offset, respectively. 127 Acquisition was achieved in the $m / z$ 50-3000 range with a center at $m / z$ 200. TIMS separation 128 depends on the gas flow velocity $\left(v_{g}\right)$, elution voltage $\left(V_{\text {elution }}\right)$, ramp time $\left(t_{\text {ramp }}\right)$, base voltage $129\left(V_{\text {out }}\right)$ and the electric field $(\vec{E})$. The reduced mobility, $K_{0}$, can be calculated as follows :

$$
\mathrm{K}_{0}=\frac{v_{g}}{\vec{E}}=\frac{A}{\left(V_{\text {elution }}-V_{\text {out }}\right)}(\text { Eq. 1) }
$$

131 The mobility calibration constant $A$ was determined using known reduced mobilities of tuning 132 mix components. The resolving power $(R)$ and resolution $(r)$ are defined as $R=\left(1 / \mathrm{K}_{0}\right) / w$ and $133 r=1.18 \times\left[\left(1 / \mathrm{K}_{0}\right)_{2}-\left(1 / K_{0}\right)_{1}\right] /\left(w_{1}+w_{2}\right)$, where $w$ is the full peak width at half-maximum.

134 To improve separation efficiency, scan rate $\left(S r=\Delta \mathrm{V}_{\text {ramp }} / \mathrm{t}_{\text {ramp }}\right)$ was tuned thank to imeX $\mathrm{X}^{\mathrm{TM}}$ 135 technology. For this, $t_{\text {ramp }}$ is automatically set as function of manually adjusted $\Delta V_{\text {ramp }} . \mathrm{N}_{2}$ was 136 used as buffer gas at funnel temperature $(\mathrm{T}=305 \mathrm{~K})$ with $v_{g}$ set by the pressure difference of 1370.169 mbar. A potential of $350 \mathrm{Vpp}$ was applied to radially confine the trapped ion cloud. The 138 measured inverse reduced mobilities were converted into collision cross sections (CCS) using the 139 Mason-Schamp equation:

$$
\Omega=\frac{(18 \pi)^{1 / 2}}{16} \times \frac{q}{\left(k_{B} \times T\right)^{1 / 2}} \times\left[\frac{1}{m_{i}}+\frac{1}{m_{g}}\right]^{1 / 2} \times \frac{1}{N} \times \frac{1}{\mathrm{~K}_{0}}(\text { Eq. } 2)
$$


141 where $q$ is the ion charge, $k_{B}$ is the Boltzmann constant, $N$ is the gas number density, $m_{i}$ is the

142 ion mass, and $m_{g}$ is the gas molecule mass. TIMS-MS spectra and mobilograms were analyzed

143 using Compass Data Analysis 5.1 (Bruker).

$144 \quad 2.6$ ESI-TIMS-MS analysis of the trisaccharides.

145 Throughout this study, isomeric trisaccharides were analysed in the positive ion mode as singly

146 charged ions without any salt doping at $\mathrm{m} / \mathrm{z} 505.176,522.203,527.158$ and 543.132 for proton,

147 ammonium, sodium and potassium adducts, respectively. Separation occurred according to their

148 mobility. All samples was continuously infused at $5 \mu$ L. $\mathrm{min}^{-1}$ via a $250 \mathrm{~mL}$ syringe.

$149 \quad$ 2.7 Theoretical Collision Cross Section Calculations.

150 All initial geometry relaxations were performed using the Merck molecular force field

151 (MMFF94) implemented in Avogadro (v1.2). Geometry optimization was finalized using density

152 functional theory (DFT) calculations with NWChem (v7.0). Theoretical CCS calculations were

153 carried out in IMoS (v.1.1) using the average of ten trajectory method processes (Larriba \& Ho-

154 gan, 2013).

$155 \quad 2.8$ Data analysis.

156 Statistical tests and Principal component analysis (PCA) were performed using Origin Pro 2016

157 (OriginLab Corporation, MA, USA.)

\section{3. RESULTS AND DISCUSSION}

$159 \quad 3.1$ Ion mobility and collision cross sections determination of the library of trisaccharides.

160 As observed elsewhere the type of adducts exhibits different dependencies upon the identity of

161 the bound cation, influencing the measured ion mobility (Huang \& Dodds, 2013, 2015; Zheng,

162 Zhang, et al., 2017). Nevertheless, for a given trisaccharide, the ion mobility did not necessarily

163 increase/decrease proportionally according to the protonated form or ionic radii of the alkali 
164 metal adduct as $154 \mathrm{pm}, 99 \mathrm{pm}, 137 \mathrm{pm}$ and $151 \mathrm{pm}$ for $\mathrm{Na}^{+}, \mathrm{K}^{+}$and $\mathrm{NH}_{4}{ }^{+}$, respectively. Most

165 importantly, it clearly appeared that the size of the adduct was not the only factor affecting the

166 ion mobility, since it can be a hypothesised that each carbohydrate can adopt a preferred -most

167 stable- conformation, which can be either close or distinct according to a given cation. As re-

168 ported in Table 1, type of adduct can affect results at two level: (i) By supporting a straightfor-

169 ward identification. The mobility of two trisaccharide isomers, e.g. isomaltoriose and raffinose,

170 cannot be discriminated using protonated forms (both with $1 / \mathrm{K}_{0}=1.000 \mathrm{~V} . \mathrm{s} / \mathrm{cm}^{2}$ ) but unambigu-

171 ously distinguished via ammoniated $\left(1 / \mathrm{K}_{0}=1.034\right.$ versus $1.001 \mathrm{~V} . \mathrm{s} / \mathrm{cm}^{2}$, respectively), sodiated

$172\left(1 / \mathrm{K}_{0}=1.033 / 0.984\right.$ versus $1.020 \mathrm{~V} \cdot \mathrm{s} / \mathrm{cm}^{2}$, respectively $)$, or potassied adduct $\left(1 / \mathrm{K}_{0}=1.040 / 0.988\right.$

173 versus $1.027 \mathrm{~V} . \mathrm{s} / \mathrm{cm}^{2}$, respectively). In this case, an increase in the size of the alkali metal ion

174 allowed the two isomers to assume conformations which were more readily distinguished by

175 mobility. (ii) By revealing other potential forms of trisaccharide such as epimers, connectivity

176 isomers or more simply other conformations due to distinct adduction sites. The mobility of two

177 forms for a given trisaccharide, e.g. sodiated and potassied 4'galactosyllactose yields to one and

178 two peaks detected by ion mobility $\left(1 / \mathrm{K}_{0}=0.990\right.$ versus 1.006 and $1.018 \mathrm{~V} . \mathrm{s} / \mathrm{cm}^{2}$, respectively).

179 Moreover, after thorough examination of the various values summarized in table 1, and except

180 potential traces of maltotriose in isomaltoriose sample, as revealed by potassium adduct $\left(1 / \mathrm{K}_{0}=\right.$

1811.041 versus $1.040 \mathrm{~V} . \mathrm{s} / \mathrm{cm}^{2}$, respectively), none standard trisaccharide seems to contain residual

182 presence of other one investigated in the herein study. One of the most emblematic features of

183 ion mobility hold in its ability to discriminate isomeric forms even with subtle variation. To ex-

184 plore the potential of timsTOFTM as regards such aforementioned aim, results on four trisaccha-

185 rides namely maltotriose, 
Table 1. Recapitulative of the inverse reduced mobility of the 13 studied trisaccharides under various adducted forms at a scan rate of $5.5 \mathrm{~V} / \mathrm{ms}$ and deducted collision cross section.

\begin{tabular}{|c|c|c|c|c|}
\hline \multirow{2}{*}{ Name } & \multirow{2}{*}{ Adduct } & \multirow{2}{*}{$\begin{array}{c}1 / \mathrm{K}_{0} \\
\left(\mathrm{~V} . \mathrm{s} . \mathrm{cm}^{-2} \text { ) }\right.\end{array}$} & \multicolumn{2}{|c|}{${ }^{\text {TIMS }} \mathrm{CCS}_{\mathrm{N}_{2}}\left(\AA^{2}\right)$} \\
\hline & & & Experimental* & Theoretical \\
\hline \multirow{4}{*}{ Maltotriose } & $\mathrm{H}$ & 1.000 & 205.8 & $205.9 \pm 3.7$ \\
\hline & $\mathrm{NH}_{4}$ & 1.006 & 206.8 & $206.7 \pm 4.1$ \\
\hline & $\mathrm{Na}$ & 1.038 & 213.3 & $214.2 \pm 6.2$ \\
\hline & $\mathrm{K}$ & $1.052 / 1.041$ & $216.0 / 213.8$ & $216.4 \pm 4.8$ \\
\hline \multirow{4}{*}{ Isomaltotriose } & $\mathrm{H}$ & 0.997 & 205.2 & $205.0 \pm 4.8$ \\
\hline & $\mathrm{NH}_{4}$ & 1.034 & 212.6 & $212.6 \pm 2.8$ \\
\hline & $\mathrm{Na}$ & $1.033 / 0.984$ & $212.3 / 202.1$ & $212.8 \pm 4.8$ \\
\hline & $\mathrm{K}$ & $1.040 / 0.988$ & $213.5 / 203.0$ & $213.5 \pm 3.3$ \\
\hline \multirow{4}{*}{ Raffinose } & $\mathrm{H}$ & 0.997 & 205.2 & $205.3 \pm 2.7$ \\
\hline & $\mathrm{NH}_{4}$ & 1.001 & 206.1 & $206.4 \pm 3.8$ \\
\hline & $\mathrm{Na}$ & 1.020 & 209.5 & $210.6 \pm 5.6$ \\
\hline & $\mathrm{K}$ & 1.027 & 211.0 & $211.3 \pm 3.8$ \\
\hline \multirow{4}{*}{ Melezitose } & $\ddot{\mathrm{H}}$ & 0.999 & 205.5 & $205.4 \pm 2.9$ \\
\hline & $\mathrm{NH}_{4}$ & 1.003 & 206.3 & $206.2 \pm 4.2$ \\
\hline & $\mathrm{Na}$ & 0.982 & 201.8 & $202.4 \pm 3.2$ \\
\hline & $\mathrm{K}$ & 0.986 & 202.6 & $203.2 \pm 3.1$ \\
\hline \multirow{4}{*}{ 1-Kestose } & $\mathrm{H}$ & 0.995 & 204.7 & $204.6 \pm 3.9$ \\
\hline & $\mathrm{NH}_{4}$ & 1.013 & 208.3 & $208.2 \pm 2.9$ \\
\hline & $\mathrm{Na}$ & 0.999 & 205.5 & $206.7 \pm 5.2$ \\
\hline & $\mathrm{K}$ & 1.009 & 207.1 & $207.5 \pm 4.5$ \\
\hline \multirow{4}{*}{ Gentianose } & $\mathrm{H}$ & 1.003 & 206.3 & $206.5 \pm 4.7$ \\
\hline & $\mathrm{NH}_{4}$ & 1.036 & 213.0 & $213.4 \pm 4.3$ \\
\hline & $\mathrm{Na}$ & $1.016 / 0.985$ & $208.7 / 202.4$ & $208.0 \pm 6.1$ \\
\hline & $\mathrm{K}$ & $1.030 / 1.004$ & $211.6 / 206.2$ & $211.3 \pm 2.4$ \\
\hline \multirow{4}{*}{ Panose } & $\mathrm{H}$ & 0.995 & 204.7 & $204.6 \pm 4.4$ \\
\hline & $\mathrm{NH}_{4}$ & 1.007 & 207.0 & $206.8 \pm 3.5$ \\
\hline & $\mathrm{Na}$ & $1.018 / 1.025 / 0.981$ & 209.2/210.7/201.6 & $209.3 \pm 7.0$ \\
\hline & $\mathrm{K}$ & $1.005 / 1.032$ & $206.3 / 211.9$ & $206.5 \pm 3.9$ \\
\hline \multirow{4}{*}{ Cellotriose } & $\mathrm{H}$ & $1.021 / 1.070$ & $210.2 / 220.1$ & $210.4 \pm 3.7$ \\
\hline & $\mathrm{NH}_{4}$ & 1.042 & 214.1 & $214.3 \pm 3.3$ \\
\hline & $\mathrm{Na}$ & $1.041 / 1.023$ & $213.9 / 210.2$ & $213.7 \pm 5.9$ \\
\hline & $\mathrm{K}$ & 1.048 & 215.2 & $214.9 \pm 3.4$ \\
\hline \multirow{4}{*}{ Laminatriose } & $\mathrm{H}$ & $1.021 / 1.073$ & $210.1 / 220.7$ & $210.1 \pm 4.2$ \\
\hline & $\mathrm{NH}_{4}$ & 1.062 & 218.3 & $218.3 \pm 4.5$ \\
\hline & $\mathrm{Na}$ & 1.029 & 211.5 & $211.3 \pm 5.6$ \\
\hline & $\mathrm{K}$ & $1.043 / 0.982$ & $214.1 / 201.7$ & $214.0 \pm 3.4$ \\
\hline \multirow{4}{*}{ Mannotriose } & $\mathrm{H}$ & 1.040 & 213.9 & $213.9 \pm 3.9$ \\
\hline & $\mathrm{NH}_{4}$ & 1.039 & 213.6 & $213.5 \pm 3.8$ \\
\hline & $\mathrm{Na}$ & 1.028 & 211.4 & $212.0 \pm 5.2$ \\
\hline & $\mathrm{K}$ & 1.041 & 213.7 & $214.0 \pm 2.1$ \\
\hline \multirow{4}{*}{ 4'galactosyllactose } & $\mathrm{H}$ & $0.998 / 1.014$ & $205.3 / 208.5$ & $20509 \pm 4.1$ \\
\hline & $\mathrm{NH}_{4}$ & $0.995 / 1.014$ & $204.6 / 208.7$ & $204.7 \pm 4.6$ \\
\hline & $\mathrm{Na}$ & 0.990 & 203.5 & $203.7 \pm 6.2$ \\
\hline & $\mathrm{K}$ & $1.006 / 1.018$ & $206.6 / 209.1$ & $206.9 \pm 3.6$ \\
\hline \multirow{4}{*}{ Inulotriose } & $\mathrm{H}$ & 1.053 & 216.7 & $216.8 \pm 2.8$ \\
\hline & $\mathrm{NH}_{4}$ & 1.045 & 214.7 & $214.9 \pm 3.3$ \\
\hline & $\mathrm{Na}$ & 0.992 & 203.9 & $203.9 \pm 5.9$ \\
\hline & $\mathrm{K}$ & $0.986 / 1.004$ & $202.6 / 206.3$ & $202.9 \pm 3.2$ \\
\hline \multirow{4}{*}{ Erlose } & $\mathrm{H}$ & 0.991 & 203.9 & $204.6 \pm 3.6$ \\
\hline & $\mathrm{NH}_{4}$ & 0.990 & 203.4 & $203.8 \pm 3.6$ \\
\hline & $\mathrm{Na}$ & 1.007 & 206.9 & $208.4 \pm 5.1$ \\
\hline & $\mathrm{K}$ & 0.990 & 203.3 & $203.5 \pm 4.2$ \\
\hline
\end{tabular}


190 isomaltotriose, cellotriose and mannotriose under the various adducts were compared. Such

191 choice was motivated by differences in: i) connectivity, with isomaltotriose/maltotriose ( $\alpha$-D-

192 Glc $(1 \rightarrow 6) / \alpha-D-G l c(1 \rightarrow 4)$, ii) anomery, with maltotriose/cellotriose ( $\alpha$-D-Glc $(1 \rightarrow 4) /(\beta-D-$

$193 \mathrm{Glc}(1 \rightarrow 4))$ and iii) composition, with cellotriose/ mannotriose $(\beta$-D-Glc $(1 \rightarrow 4)$ versus $\beta$-D-Man

$194(1 \rightarrow 4))$ (Figure 1). Examination of protonated forms shows that only a slight mobility difference

195 occurred between the linkage isomers $(1 \rightarrow 6$ versus $1 \rightarrow 4)$, with $0.997 \mathrm{~V} . \mathrm{s} / \mathrm{cm}^{2}$ and $0.995 \mathrm{~V} . \mathrm{s} / \mathrm{cm}^{2}$

196 for isomaltotriose and maltotriose, respectively (Figure 1a brown and blue trace, respectively).

197 Varying $\alpha$ - to $\beta$ - linkage, it reveals a significant shift from $0.995 \mathrm{~V} . \mathrm{s} / \mathrm{cm}^{2}$ to 1.021 and 1.070

198 V.s $/ \mathrm{cm}^{2}$ for maltotriose to cellotriose, respectively (Figure 1a blue and green trace, respectively).

199 The detection of two peaks, with similar abundance for cellotriose, can be putatively ascribed to

200 either the presence of two equivalent protomers and/or to the co-existence of both $\alpha$ - and $\beta$ -

201 anomers. Using a different fully compositional isomer, one exhibits also a different mobility

202 from 1.021/1.070 V.s/ $/ \mathrm{cm}^{2}$ to $1040 \mathrm{~V} . \mathrm{s} / \mathrm{cm}^{2}$ for cellotriose to mannotriose, respectively (Figure 1a

203 green and pink trace, respectively). In contrast to protonated forms, the ammoniated ones present

204 a better difference like for isomalototriose/maltotriose couple with 1.034/1.006 V.s/ $/ \mathrm{cm}^{2}$ (Figure

$2051 \mathrm{~b}$, brown and blue trace, respectively), and for maltotriose/cellotriose one with 1.006/1.042

206 V.s $/ \mathrm{cm}^{2}$ (Figure 1b, blue and green trace, respectively). Mobility values were quasi similar for

207 cellotriose/mannotriose one with 1.042/1.039 V.s/ $\mathrm{cm}^{2}$ (Figure 1b, green and pink trace, respec-

208 tively) impairing any discrimination between us in such conditions. However, it was quoted out

209 that with ammonium, only one peak is detected for the four carbohydrates even for cellotriose

210 while two peaks were observed for protonated one. It seems to indicate that either only one am-

211 monium attachment site exists or that an absence of interconversion occurrs during the course of 
212 the experiment. Under sodiated forms, isomaltotriose shows two distinct peaks at 0.984 and

2131.033 V.s/cm² but differing

214

215

216

217

218

219

220

221

222

223

224

225

226

227

228

229

230

231

232

233

234

235

236

237

238

239

240

241

242

243

244

245

246

247

248

249

250

251

252

253

254

255

256

257

258

259

260

261

262

263

264

265 a) $\times$

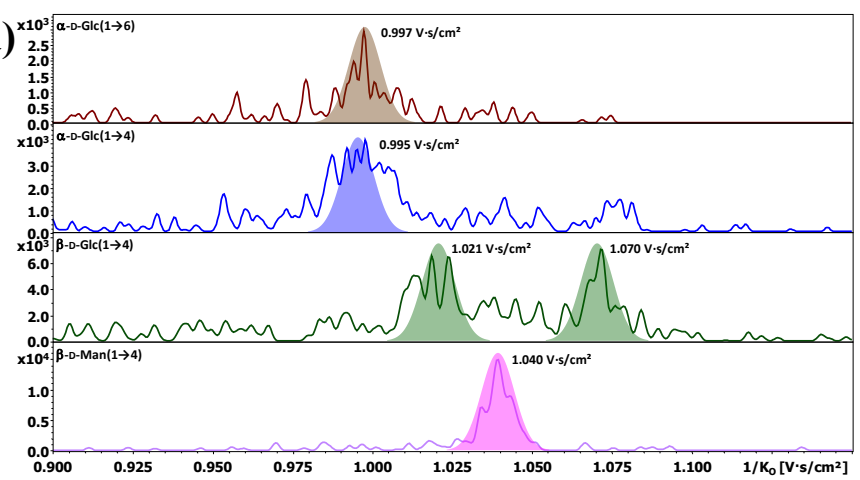

b) $)_{1}^{\mathbf{1}}$

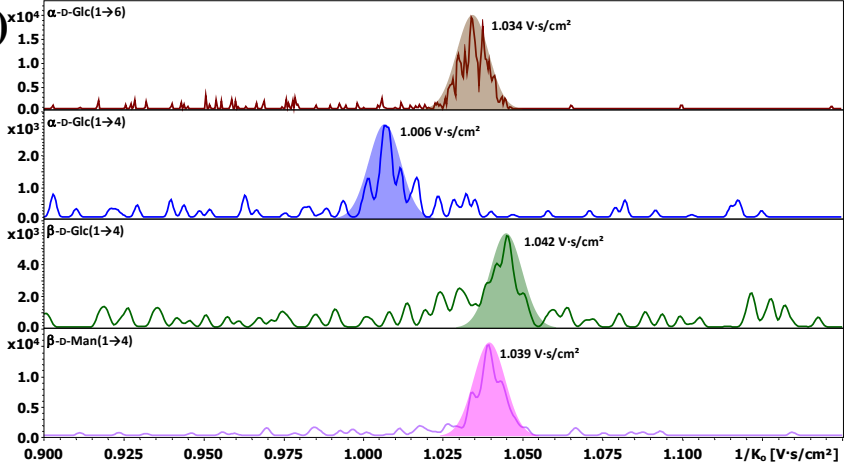

$\times 6.0 .0 .0-D-G l c(1 \rightarrow 6)$

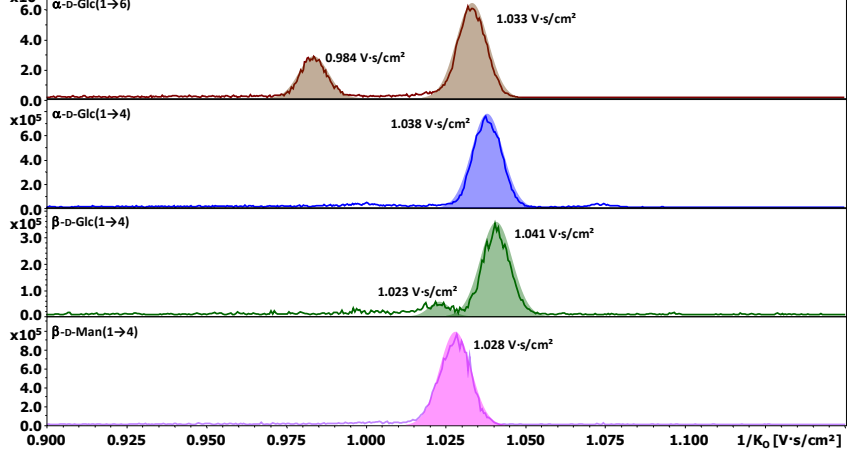

d)

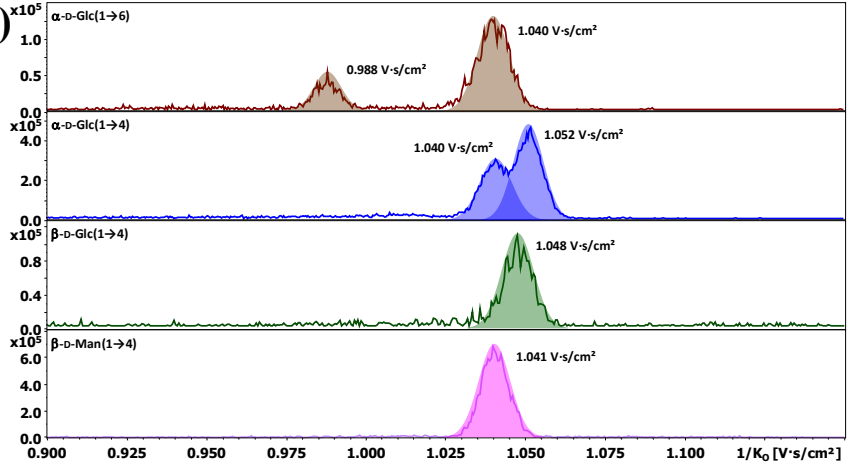

Figure 1. TIMS based mobilograms without any smoothing for trisaccharides showing difference in connectivity: $\alpha$-D-Glc $(1 \rightarrow 6)$ versus $(\alpha-\mathrm{D}-\mathrm{Glc}(1 \rightarrow 4)$ (isomaltotriose versus maltotriose), 
anomery $((\alpha-\mathrm{D}-\mathrm{Glc}(1 \rightarrow 4)$ versus $(\beta$-D-Glc $(1 \rightarrow 4)$ (maltotriose versus cellotriose) and composition: $\beta$-D-Glc $(1 \rightarrow 4)$ versus $\beta$-D-Man $(1 \rightarrow 4)$ (cellotriose versus mannotriose) for a) singly protonated, b) singly sodiated, c) singly ammoniated and d) singly potassied trisaccharides. Measurement was achieved at a scan rate of $5.5 \mathrm{~V} / \mathrm{ms}$. from the unique one recorded at $1.038 \mathrm{~V} . \mathrm{s} / \mathrm{cm}^{2}$ for maltotriose (Figure 1c, brown and blue trace, respectively). This last one is very close from its $\beta$ - anomer, cellotriose, with a mobility at 1.041 V.s/ $\mathrm{cm}^{2}$ (Figure 1c, green trace). Moreover, as for protonated form, a second but lower peak was detected at $1.023 \mathrm{~V}$.s $/ \mathrm{cm}^{2}$. Sodiated mannotriose exhibits lower mobility shift $\left(1.028 \mathrm{~V} . \mathrm{s} / \mathrm{cm}^{2}\right.$,

274 Figure 1c, pink trace). Again with sodium, one can hypothesize that the observation of only one mobility peak from maltotriose and mannotriose may be attributed to its inability to mutarotate, and present two distinct $\alpha / \beta$ anomers at the $\mathrm{OH}$ group of $\mathrm{C}-1$. The isomaltotriose and cellotriose both displayed two mobility features, presumably due to its $\alpha / \beta$ mutarotation, while maltotriose 278 and mannotriose only displayed one such feature, perhaps due to the influence of the composi279 tion or linkage on mutarotation, and leading to a preference for only a single $\alpha$ or $\beta$ anomer. 280 Nonetheless, at this stage, it cannot be completely excluded that the two mobility peaks observed 281 for isomaltotriose and cellotriose would result from different sodium attachment locations. As 282 regards potassied forms, similar behaviour than for sodiated ones were obtained but with higher 283 mobility values. However, two exceptions were highlighted for maltotriose and cellotriose. For 284 the former, two unresolved peaks were detected at $1.040 \mathrm{~V} . \mathrm{s} / \mathrm{cm}^{2}$ and $1.052 \mathrm{~V} . \mathrm{s} / \mathrm{cm}^{2}$ (Figure $1 \mathrm{~d}$, 285 blue trace) instead of only one with sodium (Figure 1c, blue trace). For the latter, only one peak 286 was detected at 1.048 V.s/cm ${ }^{2}$ (Figure 1d, green trace), instead of two with sodium (Figure 1c, 287 green trace). Taking into account the results obtained for all trisaccharides (Table 1 and Figure 288 1), some general trends can be drawn where non-reducing trisaccharides (raffinose, melezitose, 289 1-kestose, gentianose, inulotriose, erlose) were higher in mobility, i.e. smaller in collision cross 290 section or more compact in nature than the reducing ones (maltotriose, isomaltotriose, panose, 
291 cellotriose, laminaritriose, mannotriose, 4'galactosyllactose). Additionally, the former exhibits

292 only one mobility peak, and thus as speculated above, we have reasonably attributed this obser-

293 vation to a 'locked' configuration at the anomeric carbon, while the latter i.e. their reducible

294 counterparts lead to two mobility peaks, potentially from $\alpha / \beta$ anomeric configurations as previ-

295 ously suggested (Nagy et al., 2018). However, it must keep in mind that the coexistence of mul-

296 tiple cation attachment sites or impurities at traces level can also exist and that may explain the

297 results of sodiated and potassied gentianose as well as potassied inulotriose. Moreover, for a

298 given monosaccharide composition, comparison of $\alpha$ versus $\beta$ linked trisaccharides reveals that

299 the $\beta$ linked was more elongated (higher inverse reduced mobility i.e. lower mobility) than the $\alpha$ -

300 linked (lower inverse reduced mobility i.e. higher mobility). In summary, TIMS experiments

301 achieved until now at a defined scan rate $(\mathrm{Sr})$ of $5.5 \mathrm{~V} / \mathrm{ms}$, and taking into account the type of

302 adduct, compositional isomers, regioisomers and anomers, can be distinguished readily from

303 each other on the basis of their elution voltage converted to ion mobility values and calculated

304 CCS. Herein CSS values are in good agreement with some previously reported in literature (Ta305 ble S1).

\section{$306 \quad 3.2$ Enhancing isomers separations by adjusting ion mobility resolution.}

307 The diminishment of $S r$, aiming to reduce/avoid excessive ion mobility peak overlapping, sig308 nificantly increases the mobility resolving power by $\approx 1.7$ to 4 fold. As example, for singly 309 potassied 4'galactosyllactose, $\mathrm{Sr}$ adjusted from $5.5 \mathrm{~V} / \mathrm{ms}$ to $0.6 \mathrm{~V} / \mathrm{ms}$ followed by $0.3 \mathrm{~V} / \mathrm{ms}$ as

310 the lowest scan value, led to high mobility resolving power ( $\mathrm{R} \sim 87 / 92,150 / 153$ to $175 / 183$, re-

311 spectively) (Figure 2a). Even if the presence of two peaks issued from potassied

3124 'galactosyllactose was already distinguishable at $S r=5.5 \mathrm{~V} / \mathrm{ms}$, lowering $S r$ offers a substantial

313 enhancement of mobility resolution leading to a partial and almost complete baseline resolution 
314 with $\mathrm{r}=0.7,1.0$ and 1.3, respectively. Conversely, in the case of sodiated inulotriose only one

315 large peak was initially detected. Varying $S r$ led to a significant increase of the mobility resolv-

316 ing power as well as $\mathrm{R} \sim 66,133-170$ and $137-226$, for $\operatorname{Sr} 5.5,0.6$ and $0.3 \mathrm{~V} / \mathrm{ms}$, respectively.

333 It has thus permitted to highlight the presence of three different forms (Figure 2b). Such en-

334 hancement resulted in a possible mobility resolution $\mathrm{r}=0.5$ for peak $1 / 2$ at $S r=0.6 \mathrm{~V} / \mathrm{ms}$, which

335 is slightly improved with $r=0.7$ and 0.6 for peak $1 / 2$ and $2 / 3$, respectively, at $S r=0.3 \mathrm{~V} / \mathrm{ms}$.

336 However, it was quoted out that each diminishment of $\mathrm{Sr}$ yields also to a slightly and gradual 337 loss of sensitivity. 
340 Nowadays, traceability of foodstuff is of prime importance to ensure the highest level of con341 sumer protection. Products must fulfil the criteria of quality that, day by day, are becoming more

342 and more specific and exigent. Implemented detection and quantification methods are mainly

343 based on chromatography. They are continuously improved to address the more and more restric-

344 tive quality rules of food industry, requiring the highest sensitivity. Such analytical methods

345 should afford to reveal the conformity of the products, especially as regards possible contamina-

346 tion or adulteration, which can be hazardous to health or bias the real nutritional value. Honey is

347 one of the most complex mixture of carbohydrates produced in nature and represents a good ex-

348 ample since it is subject to these same demands. Literature reports that carbohydrate content of

349 natural honey is mainly composed of monosaccharides (essentially glucose and fructose), disac-

350 charides and trisaccharides at a level of 50-70\%, 15-35\% and 2-10\%, respectively (Sanz et al.,

351 2005). Presence of several oligosaccharides, portray only minority of the whole carbohydrates

352 content, but can constitute a fingerprint indexing the honey authenticity and floral origin. Fur-

353 thermore, examination of literature showed that if mono- and disaccharides content are the

354 mainly studied carbohydrates during honeys analysis, trisaccharides have potential to be finer

355 discriminating factor (Kaškonienè, V. \& Venskutonis, P. R. 2010). Our TIMS approach was ap-

356 plied to reveal, identify and gain relative content of trisaccharides in honeys. As example, a for-

357 est based honey was infused and analysed by TIMS using a $S r$ of $0.6 \mathrm{~V} / \mathrm{ms}$. Resulting mobilo358 gram showed two intense partially resolved peaks at $1 / \mathrm{K}_{0}=0.982$ and $0.999 \mathrm{~V} . \mathrm{s} / \mathrm{cm}^{2}$ and one

359 with a lower abundance but with a very large mobility range distribution, mainly unresolved,

360 centred around 1.025 V.s $/ \mathrm{cm}^{2}$ (Figure 3a, top mobilogram). It can be also quoted out that the 361 mobility range from 0.965 to $1.055 \mathrm{~V} . \mathrm{s} / \mathrm{cm}^{2}$, ascribed to all detected peaks from honey, can theo- 
362 retically correspond to twelve among the thirteen studied trisaccharides herein. A comparative

363 GC-MS analysis was achieved, where 7 trisaccharides were identified among them i.e. raffinose,

364 1-kestose, erlose, melezitose, maltotriose, panose and isomaltotriose (Figure S2). A mixture con-

365 taining these seven standard trisaccharides at $10 \mu \mathrm{M}$ (Mix dp3, see experimental section) was

366 prepared. The mobilogram of Mixdp3 unambiguously confirms the presence of melezitose and

367 1-kestose ascribed to the two predominant peaks observed by ion mobility. Erlose can also be

extracted from

369

370

371

372

373

374

375

376

377

378

379

380

381

382

383

384

385

386

387

388

389

390

391

392

393

394

395

396

397

398

399

400

401

402

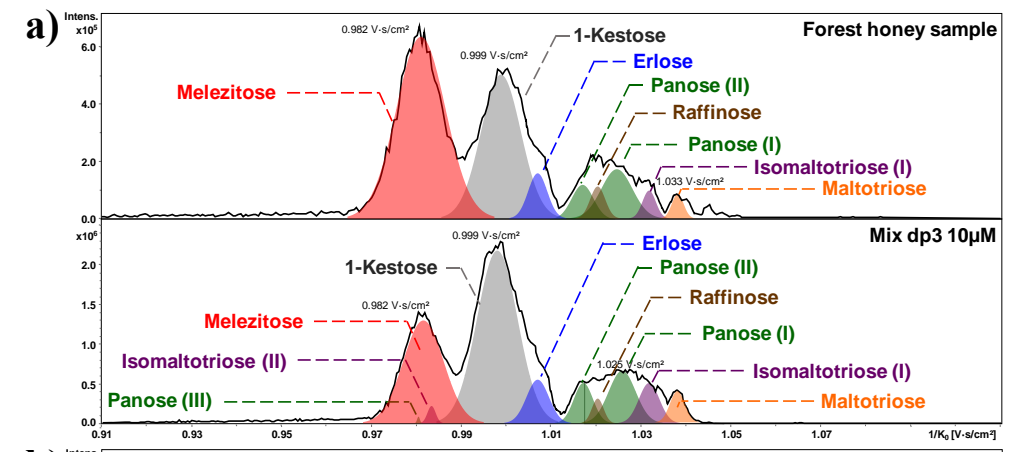

b)

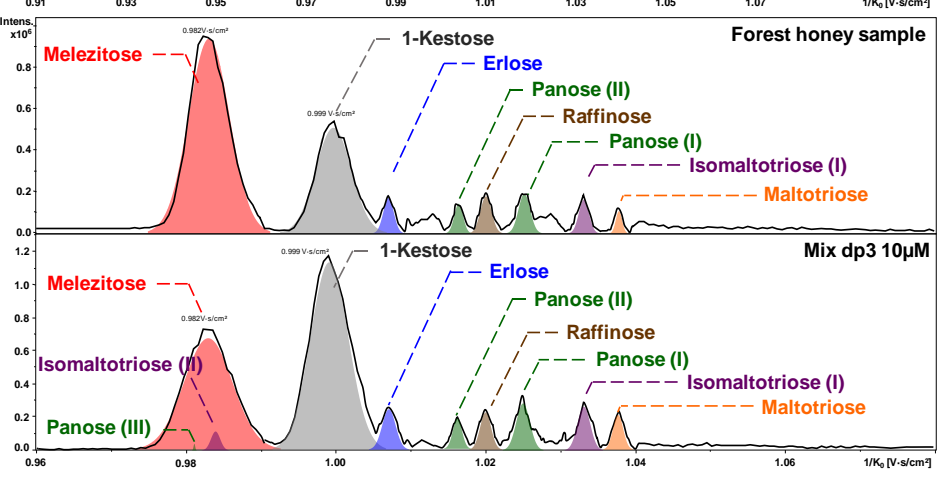

Figure 3. TIMS based mobilogram of the various singly sodiated trisaccharides ions of both standard mixture (top) and forest honey (below) acquired with the scan ratio of a) $0.6 \mathrm{~V} / \mathrm{ms}$ and b) $0.3 \mathrm{~V} / \mathrm{ms}$.

the abnormal peak tailing of 1-Kestose peak. The deconvolution of the large mobility distribution in the 1.012-1.042 V.s/ $/ \mathrm{cm}^{2}$ range allows the putative assignment of panose, raffinose, isomaltotriose and maltotriose (Figure 3a, below mobilogram). For melezitose, 1-kestose/erlose and maltotriose, the resolving power $(R)$ is 84,69 and 201, respectively, while the unresolved peak of the 
403 set constituted of panose, raffinose and isomaltotriose is only 54. As regards resolution (r), val404 ues of $0.77,0.80$ and 0.77 for melezitose to 1-kestose/erlose, 1-kestose/erlose to unresolved set 405 and unresolved set to maltotriose, respectively, were obtained. Nonetheless, it appears clearly 406 that a complete mobility resolution is a mandatory condition to fully address the unambiguous 407 and straightforward identification of the carbohydrates in crude samples. To reach that, a $\mathrm{Sr}$ of $408 \quad 0.3 \mathrm{~V} / \mathrm{ms}$ was applied leading to a substantial improvement of both resolving power and mobility 409 resolution with a close baseline resolution for every compounds (Figure 3b). Specifically, with 410 such settings, erlose trace can be easily discriminated from 1-kestose, as well as the full set of 411 panose, raffinose, isomaltotriose and maltotriose. Using lower scan rates yields to clear im412 provement in both $R$ and $r$ with all values included in the range 126-722 and 1.15-2.19, respec413 tively. It contrasts with results obtained elsewhere as raffinose, isomaltotriose, melezitose and 414 maltotriose were not separated under $[\mathrm{M}+\mathrm{Na}]^{+}$and were hardly resolved with a maximal $r=$ $4150.25,0.52,1.42,0.27,1.15$ and 0.87 for maltotriose-isomaltotriose, maltotriose-raffinose, malto416 triose-melezitose, isomaltotriose-raffinose, isomaltotriose-melezitose and raffinose-melezitose 417 couple, respectively (Xie et al., 2020). Our GC-MS analysis showed similar profile to those pre418 viously observed by Sanz et al. (Sanz, M.L., Sanz, J., \& Martínez-Castro, I. (2004) and de la 419 Fuente et al. (2011) as regards elution order and observation of possible $Z$ and $E$ isomers for mal420 totriose, isomaltotriose and panose (Figure S2). Nonetheless, several peaks for aforementioned 421 trisaccharides are also systematically observed without any derivatization (Figure 3 and Table 1). 422 Such results suggest that configurational isomers pre-exist before derivatization due to $\alpha / \beta$ mu423 tarotation, as evocated in section 3.1. Moreover, our TIMS approach overcomes frequent co424 elution problems observed with non-polar GC columns, especially between raffinose and kesto425 ses that may lead to misestimation (Sanz, M.L., Sanz, J., \& Martínez-Castro, I., 2004; Ruiz- 
426 Matute et al., 2010; de la Fuente et al., 2011). All $R$ and $r$ metrics are listed in Table S2. Interest-

427 ingly, beyond only qualitative determination (identification criterion), one can access to a rela428 tive quantification (relative content criterion), providing to take into account the variation in re429 sponse factor due to various ionization efficiency by comparing signals from independent analy430 sis of the molecules alone or in mixture. Therefore, area integration allows establishing the rela431 tive content of the honeys as regards the seven trisaccharides. In this sense, TIMS approach re432 veals a similar abundance order both with $S r=0.6$ and $0.3 \mathrm{~V} / \mathrm{ms}$ as follows: melezitose (28.2$43328.3 \%)>\operatorname{raffinose}(20.8-21.4 \%)>$ panose $(13.7 \%)>$ erlose $(12.2-12.6 \%)>1$-kestose $(10.5-$ $43410.8 \%)>$ maltotriose $(8.4-8.5 \%)>$ isomaltotriose $(5.1-5.7 \%)$. Such content matched very well 435 with those obtained by GC-MS analysis (Table 2). Both nature and relative abundance of trisac436 charides can represent a potential signature of the floral sources (Cotte et al., 2003; Kaškonienè $437 \&$ Venskutonis, 2010). The data obtained for the seven carbohydrates and from the five honeys 438 (Table S3) were analyzed in a one-way ANOVA. Results ported that all overall ANOVA $p$-value 439 are smaller than 0.05 (95\% confidence interval), hence at least two of the five honey have sig440 nificantly different means whatever the given trisaccharides. Further statistical treatment by us441 ing Tukey test, i.e. mean comparisons, reveals further information regarding relationships be442 tween honeys (Table S4 and Figure S3). 
445 Table 2. Relative content of the seven positively identified trisaccharides according to both the two-based TIMS scan ratio $(\mathrm{Sr})$ and GC-MS for the forest honey.

\begin{tabular}{|c|c|c|c|}
\hline \multirow{3}{*}{ Identified trisaccharides } & \multicolumn{3}{|c|}{ Relative content $(\%)(\mathrm{n}=10)$} \\
\hline & \multicolumn{2}{|c|}{$S r$ setting } & \multirow{2}{*}{ GC-MS } \\
\hline & $0.6 \mathrm{~V} / \mathrm{ms}$ & $0.3 \mathrm{~V} / \mathrm{ms}$ & \\
\hline 1-Kestose & $10.8 \pm 1.4$ & $10.5 \pm 1.6$ & $10.6 \pm 2.3$ \\
\hline Erlose & $12.2 \pm 0.5$ & $12.6 \pm 0.5$ & $12.4 \pm 1.5$ \\
\hline Isomaltotriose & $5.1 \pm 0.7$ & $5.7 \pm 0.5$ & $5.5 \pm 1.2$ \\
\hline Maltotriose & $8.5 \pm 0.5$ & $8.4 \pm 0.5$ & $8.1 \pm 1.4$ \\
\hline Melezitose & $28.2 \pm 2.4$ & $28.5 \pm 2.1$ & $28.7 \pm 2.6$ \\
\hline Panose & $13.7 \pm 1.5$ & $13.7 \pm 1.6$ & $13.6 \pm 1.8$ \\
\hline Raffinose & $21.4 \pm 2.1$ & $20.6 \pm 1.8$ & $20.9 \pm 2.3$ \\
\hline
\end{tabular}

447

448

449

450

451

452 461 the second component where weights are both positive (maltotriose) and negative (panose). Su462 perimposition of the botanical origins represented according to the two first components, leading

All of honey seemed to be discriminated using at least two significant trisaccharides content. In addition, it appears that all the targeted trisaccharides can be used to the distinction of acacia and forest honeys on one hand and rosemary and forest honeys on the other hand. All the seven trisaccharides regarding their more or less complementary balances of significant/non-significant means as 2/8 (1-kestose, isomaltotriose, panose, raffinose), 3/7 (erlose) and 1/9 (maltotriose, melezitose) could be chosen as a relevant role authenticity/floral marker. Standardized principal component analysis can explain the $88.7 \%$ of total variance using the two first components, reaching $100 \%$ through four first components. It can be observed that the first principal component is mainly a function of melezitose and erlose. The second principal component is essentially a function of maltotriose and panose (Figure 4). In summary, the most important relative weights in the first component are both positive (melezitose) and negative (erlose), this may be interpreted as a general balance to serve as index of each honey. A similar behaviour was obtained for 
463 to the botanical origin coordinates, known as centroid, using the scores obtained for honeys 464 against their botanical origin.

465

466

467

468

469

470

471

472

473

474

475

476

477

478

479

480

481

482

483

484

485

486

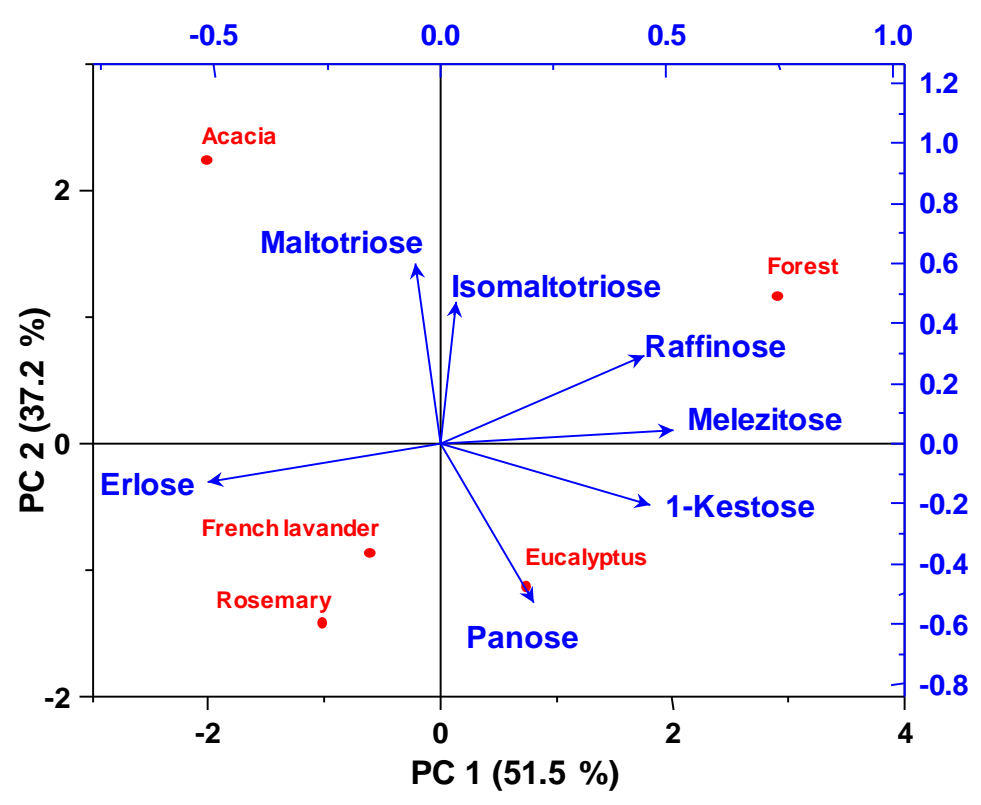

Figure 4. Superimposition of the representation of carbohydrates (blue) and of botanical origins (red) as a function of the two first principal components.

It may be seen that forest honey obtains the highest scores for the first component, while acacia and rosemary obtain the lowest. As such, the group of trisaccharides formed by melezitose, raffinose and erlose may play an important role in distinguishing among honeys of different botanical origins as observed in another study (Cotte et al. 2004). Acacia honey obtains higher scores in the second principal component than the remainder of botanical origins, above all relative to forest and much more to rosemary, eucalyptus and french lavender. Based on the two first principal components analysis and Tukey test, taking into account that all seven trisacharides were detected in the five honeys, we can suggest to use both abundance and ratio of trisaccharide as discriminant factor. For example, the herein honeys can be characterized with carbohydrates balance: forest with $\geq 20 \%$ of melezitose and $\geq 20 \%$ of melezitose/raffinose $>1$; acacia with malto- 
487 triose $>10 \%$, panose $<10 \%$ and erlose/maltotriose $>4.5 \%$; eucalyptus with panose $>15 \%$; 1 488 kestose $>5 \%$ and panose $/ 1$-kestose $>2 \%$; french lavender with maltotriose $>5 \%$, panose $>10 \%$ 489 and erlose/maltotriose $>9 \%$; rosemary with maltotriose $<5 \%$, panose $>10 \%$ and er490 lose/maltotriose $>9.5 \%$. Such factors given to depict possible discriminative tree, need to be used 491 with many precautions, since only a restricted set of honeys was assessed. Such approach should 492 be further enriched with both a larger panel of honeys and other potential but very rare trisaccha493 rides such as neo-kestose, 6-kestose, planteose or also theanderose. Another strategy holds in the 494 introduction of canonical discriminant (Nozal et al., 2005), as a potential key to achieve a 495 straightforward honeys classification, but the judicious choice of the suitable factor to consider496 ate remains a delicate approach. Indeed, if single factors as presence and/or abundance of trisac497 charides can be very effective to characterize the differences among monofloral honeys, that 498 could be a more daunting task with honeys generically classified as multifloral. Moreover, the 499 ratio between some mono-, di- or trisaccharides such as for example fructose/glucose, mal500 tose/isomaltose, sucrose/turanose, and maltose/turanose or also maltotriose/(raffinose + erlose + 501 melezitose) is another indicator that may be used to ascertain honey authenticity (Nozal et al., 502 2005). For example, an acacia honey was distinguished by a high maltose/isomaltose ratio (11:1 to 503 25:9), while this ratio for linden and honeydew honeys was remarkably lower, 2.2 and 2.0-2.5, 504 respectively (Molnár-Perl \& Horváth, 1997). A similar strategy was successfully used by Cotte et 505 al. (2003) regarding maltotriose/trisaccharides ratio to distinguish various lavender honey.

\section{4. CONCLUSIONS}

507 We demonstrate in this work that the fast and direct analysis by TIMS represents a powerful and 508 suitable alternative to longer chromatographic run, with analysis time of few minutes to more 509 than one hour, respectively, to distinguish between 13 isomeric trisaccharides. Our IM strategy 
510 has been successfully applied to 5 honeys, which are traditionally classified by time-consuming 511 and high levels of expertise requiring pollen analyses. Our TIMS method tackles these aforemen-

512 tioned bottlenecks, by introducing an orthogonal strategy using 2 parameters i.e. $\mathrm{m} / z$ and CCS.

513 After both optimization of TIMS resolution and determination of response factor due to various

514 ionization efficiency, extraction of areas from IM afforded a straightforward relative quantifica-

515 tion of trisaccharides in the honeys. Then, principal component analysis has been successfully

516 employed as a first approach to characterize the 5 honeys, showing similarities or differences in

517 trisaccharide content aiming to delineate potential floral markers. Moreover, $\mathrm{m} / \mathrm{z}$ and CCS could

518 be supplemented by upstream separation and MS/MS spectra to serve as additional dimensions.

519 Ongoing expanding of this approach to operate at middle to high throughput, with or without 520 other upstream separation methods, paves the way to the introduction of new routinely means in 521 the field of glycomics.

\section{ACKNOWLEDGMENTS}

523 This work was supported by CEA and the French Ministry of Research and National Research 524 Agency as part of the French metabolomics and fluxomics infrastructure (MetaboHUB, ANR-11525 INBS-0010 grant).

\section{REFERENCES}

527 Ashline, D. J., Lapadula, A. J., Liu, Y.-H., Lin, M., Grace, M., Pramanik, B., \& Reinhold, V. N. (2007). Car528 bohydrate Structural Isomers Analyzed by Sequential Mass Spectrometry. Analytical Chemistry, 79, 529 3830- 3842. https://doi.org/10.1021/ac062383a.

530 Ben Faleh, A., Warnke, S., \& Rizzo, T. R. (2019). Combining Ultrahigh-Resolution Ion-Mobility Spectrome531 try with Cryogenic Infrared Spectroscopy for the Analysis of Glycan Mixtures. Analytical Chemistry, 91, 4876- 4882. https://doi.org/10.1021/acs.analchem.9b00659. 
533 Carroll, J. A., Willard, D., \& Lebrilla, C. B. (1995). Energetics of cross-ring cleavages and their relevance to the linkage determination of oligosaccharides. Analytica Chimica Acta, 307, 431- 447. https://doi.org/10.1016/0003-2670(94)00514-M.

Clowers, B. H., Dwivedi, P., Steiner, W. E., Hill, H. H., \& Bendiak, B. (2005). Separation of sodiated isobaric

Cotte, J. F., Casabianca, H., Chardon, S., Lheritier, J., \& Grenier-Loustalot, M. F. (2003). Application of carbohydrate analysis to verify honey authenticity. Journal of Chromatography A, 1021, 145- 155.

Cotte, J. F., Casabianca, H., Chardon, S., Lheritier, J., \& Grenier-Loustalot, M. F. (2004). Chromatographic

Dell, A., \& Morris, H. R. (2001). Glycoprotein Structure Determination by Mass Spectrometry. Science, 291, 2351. https://doi.org/10.1126/science.1058890.

Duus, J. Ø., Gotfredsen, C. H., \& Bock, K. (2000). Carbohydrate Structural Determination by NMR Spectroscopy: Modern Methods and Limitations. Chemical Reviews, 100, 4589- 4614. https://doi.org/10.1021/cr990302n.

EGSF and IBCarb Network \& European Science Foundation. (2014). A Roadmap for Glycosciences in Europe. (Vol. 1- 1). EGSF and IBCarb Network \& European Science Foundation. A Roadmap for Glycosciences in Europe. http://ibcarb.com/wp-content/uploads/A-roadmap-for-Glycoscience-inEurope.pdf. 2014. http://ibcarb.com/wp-content/uploads/A-roadmap-for-Glycoscience-in-Europe.pdf.

Gabryelski, W., \& Froese, K. L. (2003). Rapid and sensitive differentiation of anomers, linkage, and position isomers of disaccharides using High-Field Asymmetric Waveform Ion Mobility Spectrometry 
(FAIMS). Journal of The American Society for Mass Spectrometry, 14, 265- 277. https://doi.org/10.1016/S1044-0305(03)00002-3.

Gaye, M. M., Kurulugama, R., \& Clemmer, D. E. (2015). Investigating carbohydrate isomers by IMS-CID-

IMS-MS: precursor and fragment ion cross-sections. Analyst, 140, 6922- 6932. https://doi.org/10.1039/C5AN00840A.

Gaye, M. M., Nagy, G., Clemmer, D. E., \& Pohl, N. L. B. (2016). Multidimensional Analysis of 16 Glucose Isomers by Ion Mobility Spectrometry. Analytical Chemistry, 88, 2335- 2344. https://doi.org/10.1021/acs.analchem.5b04280.

Gray, C. J., Schindler, B., Migas, L. G., Pičmanová, M., Allouche, A. R., Green, A. P., Mandal, S., Motawia, ers, C. E., \& Flitsch, S. L. (2017). Bottom-Up Elucidation of Glycosidic Bond Stereochemistry. Analytical Chemistry, 89, 4540- 4549. https://doi.org/10.1021/acs.analchem.6b04998.

Hofmann, J., Hahm, H. S., Seeberger, P. H., \& Pagel, K. (2015). Identification of carbohydrate anomers using ion mobility-mass spectrometry. Nature, 526, 241- 244. https://doi.org/10.1038/nature15388.

Hofmann, J., \& Pagel, K. (2017). Glycan Analysis by Ion Mobility-Mass Spectrometry. Angewandte Chemie International Edition, 56, 8342- 8349. https://doi.org/10.1002/anie.201701309.

Huang, Y., \& Dodds, E. D. (2013). Ion Mobility Studies of Carbohydrates as Group I Adducts : Isomer Specific Collisional Cross Section Dependence on Metal Ion Radius. Analytical Chemistry, 85, 9728- 9735. https://doi.org/10.1021/ac402133f.

Huang, Y., \& Dodds, E. D. (2015). Discrimination of Isomeric Carbohydrates as the Electron Transfer Products of Group II Cation Adducts by Ion Mobility Spectrometry and Tandem Mass Spectrometry. Analytical Chemistry, 87, 5664- 5668. https://doi.org/10.1021/acs.analchem.5b00759. 
Kaškonienė, V., \& Venskutonis, P. R. (2010). Floral Markers in Honey of Various Botanical and Geographic Origins: A Review. Comprehensive Reviews in Food Science and Food Safety, 9, 620- 634. https://doi.org/10.1111/j.1541-4337.2010.00130.x.

Laine, R. A. (1994). Invited Commentary : A calculation of all possible oligosaccharide isomers both branched

Lareau, N. M., May, J. C., \& McLean, J. A. (2015). Non-derivatized glycan analysis by reverse phase liquid and linear yields $1.05 \times 1012$ structures for a reducing hexasaccharide : The Isomer Barrier to development of single-method saccharide sequencing or synthesis systems. Glycobiology, 4, 759- 767. https://doi.org/10.1093/glycob/4.6.759. chromatography and ion mobility-mass spectrometry. Analyst, 140, 3335- 3338.

Larriba, C., \& Hogan, C. J. (2013). Ion Mobilities in Diatomic Gases : Measurement versus Prediction with Non-Specular Scattering Models. The Journal of Physical Chemistry A, 117, 3887- 3901.

McKenna, K. R., Li, L., Baker, A. G., Ujma, J., Krishnamurthy, R., Liotta, C. L., \& Fernández, F. M. (2019). Carbohydrate isomer resolution via multi-site derivatization cyclic ion mobility-mass spectrometry. Analyst, 144, 7220- 7226. https://doi.org/10.1039/C9AN01584A.

Molnár-Perl, I., \& Horváth, K. (1997). Simultaneous quantitation of mono-, di-and trisaccharides as their TMS ether oxime derivatives by GC-MS: I. In model solutions. Chromatographia, 45, 321- 327. https://doi.org/10.1007/BF02505578.

Mucha, E., González Flórez, A. I., Marianski, M., Thomas, D. A., Hoffmann, W., Struwe, W. B., Hahm, H. S., Gewinner, S., Schöllkopf, W., Seeberger, P. H., von Helden, G., \& Pagel, K. (2017). Glycan Fingerprinting via Cold-Ion Infrared Spectroscopy. Angewandte Chemie International Edition, 56, 11248- 11251. https://doi.org/10.1002/anie.201702896. 
ion manipulation

Chemical

Communication,

54,

11701- 11704. https://doi.org/10.1039/C8CC06966B.

613 National Research Council (US). (2012). Committee on Assessing the Importance and Impact of Glycomics and Glycosciences. Trans-forming Glycoscience A Roadmap for the Future. National Academies Press. ttps://www.ncbi.nlm.nih.gov/books/NBK109958/pdf/Bookshelf_NBK109958.pdf.

Nozal, M. J., Bernal, J. L., Toribio, L., Alamo, M., Diego, J. C., \& Tapia, J. (2005). The Use of Carbohydrate Profiles and Chemometrics in the Characterization of Natural Honeys of Identical Geographical Origin. Journal of Agricultural and Food Chemistry, 53, 3095- 3100. https://doi.org/10.1021/jf0489724.

Paglia, G., Williams, J. P., Menikarachchi, L., Thompson, J. W., Tyldesley-Worster, R., Halldórsson, S., Rolfsson, O., Moseley, A., Grant, D., Langridge, J., Palsson, B. O., \& Astarita, G. (2014). Ion Mobility Derived Collision Cross Sections to Support Metabolomics Applications. Analytical Chemistry, 86, 3985- 3993. https://doi.org/10.1021/ac500405x.

Ruiz-Matute A.I., Brokl M., Soria A.C., Sanz M.L., Martínez-Castro I. (2010) Gas chromatographic-mass spectrometric characterisation of tri- and tetrasaccharides in honey. Food Chemistry, 120, 637-642. https://doi.org/10.1016/j.foodchem.2009.10.050. Vitro Investigation into the Potential Prebiotic Activity of Honey Oligosaccharides. Journal of Agricultural and Food Chemistry, 53, 2914- 2921. https://doi.org/10.1021/jf0500684. 
Sanz, M.L., Sanz, J., \& Martínez-Castro, I. (2004). Gas chromatographic-mass spectrometric method for the qualitative and quantitative determination of disaccharides and trisaccharides in honey. Journal of Chromatography A, 1059, 143- 148. https://doi.org/10.1016/j.chroma.2004.09.095.

Schindler, B., Barnes, L., Renois, G., Gray, C., Chambert, S., Fort, S., Flitsch, S., Loison, C., Allouche, A.-R., 
663

spectrometry analyses. Analytical and Bioanalytical Chemistry, 409, 467- 476.

664 https://doi.org/10.1007/s00216-016-9866-4.

665 